\title{
Testing the Hypothesis of Modularity on Head Capsule in Millipede Megaphyllum bosniense (Verhoeff, 1897) (Diplopoda: Julida) ${ }^{+}$
}

\author{
Vukica Vujić* , Zvezdana Jovanović, Bojan Ilić, Luka Lučić, Boris Dudić, Sofija Pavković-Lučić and Slobodan \\ Makarov
}

Citation: Vujić, V.; Jovanović, Z.; Ilić, B.; Lučić, L.; Dudić, B.; PavkovićLučić, S.; Makarov, S. Testing the Hypothesis of Modularity on Head Capsule in Mil-lipede Megaphyllum bosniense (Verhoeff, 1897) (Dilopoda: Julida), in Proceedings of the 1st International Electronic Conference on Entomology, 1-15 July 2021, MDPI: Basel, Switzerland, doi:10.3390/IECE-10359

Published: 30 June 2021

Publisher's Note: MDPI stays neutral with regard to jurisdictional claims in published maps and institutional affiliations.

Copyright: () 2021 by the authors. Submitted for possible open access publication under the terms and conditions of the Creative Commons Attribution (CC BY) license (http://creativecommons.org/licenses /by/4.0/).
1 University of Belgrade, Faculty of Biology, Studentski Trg 16, 11000 Belgrade, Serbia; zjovanovic@bio.bg.ac.rs (Z.J.); bojan.ilic@bio.bg.ac.rs (B.I.); luka@bio.bg.ac.rs (L.L.); boris.dudic@bio.bg.ac.rs (B.D.); sofija@bio.bg.ac.rs (S.P.L.); slobodan@bio.bg.ac.rs (S.M.)

* Correspondence: vukica.vujic@bio.bg.ac.rs

+ Presented at the 1st International Electronic Conference on Entomology (IECE 2021), 1-15 July 2021; Available online: https://iece.sciforum.net/.

Abstract: Covariation of multiple parts of morphological traits (referred as morphological integration) in combination with investigation about the presence of subunites (modules), and level of integration both within and between themselves (referred as modularity), have been studied in great number of animals. The presence of modularity may have an impact on both development and evolution of the species, because separate module may develop and evolve in a separate and different way. The aim of our study was to test the hypothesis that the distal region of the head capsule is a module in millipede Megaphyllum bosniense (Verhoeff, 1897) using geometric morphometrics. Millipede samples were collected from population inhabiting Mt. Avala (near Belgrade, Serbia). Several different programs were used: MakeFan, TpsDig, CoordGen, MorphoJ, and R program. Allometry was significant for the asymmetric component (FA), so further analyses were conducted on residual values of FA. Modularity hypothesis is accepted, because our results indicated that covariance coefficients (RV) for FA had lower values than $92.86 \%$ of other RV coefficients obtained by a random contiguous partition of dorsal part of the head capsule. The scaled variance of the eigenvalues of the FA (EV) was significantly lower after than before allometry removal. Considering obtained results, distal and proximal regions of the head capsule develop and function as separate modules, which indicate that mentioned structures have different developmental pathways and functions in this julidan species.

Keywords: head shape; covariation; modules; landmarks; allometry 